\title{
Thirty-seven-year investigation of quicklime-treated soil produced by deep mixing method
}

1 Hidenori Takahashi PhD, P.E.Jp(Ci.)

Head of Group, Soil Stabilization Group, Geotechnical Engineering Division, Port and Airport Research Institute, MPAT, Yokosuka, Japan (corresponding author: takahashi-h@pari.go.jp)

2 Yoshiyuki Morikawa PhD

Director of Division, Geotechnical Engineering Division, Port and Airport Research Institute, MPAT, Yokosuka, Japan
3 Naruhiko Fujii

Researcher, Soil Stabilization Group, Geotechnical Engineering Division, Port and Airport Research Institute, MPAT, Yokosuka, Japan

4 Masaki Kitazume PhD, P.E.Jp(Ci., EM), Exec.Pro.C.E.(JSCE) Professor, Department of Civil and Environmental Engineering, Tokyo Institute of Technology, Tokyo, Japan
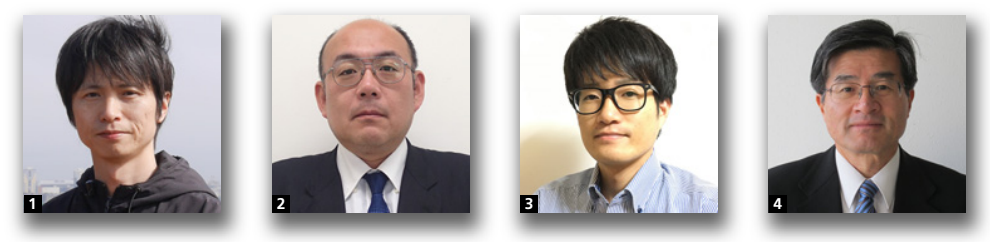

The deep mixing method was developed in Japan and Scandinavian countries in the 1970s. Subsequently, considerable research studies have been carried out on the strength characteristics of treated soil, the interaction of treated soil and surrounding soils, the development of new binders, the development of new execution machines and techniques, the establishment of design procedures and so on. However, long-term changes in the properties of treated soil have not yet been clarified. Two columns of in situ quicklime-treated soil in a soil tank for more than 37 years were analysed in this study. Laboratory tests were conducted on them at curing periods of 11, 27 and 37 years. This paper presents the change of wet density, water content, unconfined compressive strength and calcium content. Additionally, needle-penetration resistance, $\mathrm{pH}$ and electrical conductivity were measured in order to reveal the deterioration properties from the surface exposed to soil for more than $\mathbf{3 7}$ years. The results showed that the strength of the in situ quicklime-treated soil remained, even after 37 years. However, the deformation modulus tended to decrease and the treated soil deteriorated from the surface.

$\begin{array}{ll}\text { Notation } \\ E_{50} \quad \text { secant deformation modulus } \\ q_{\mathrm{n}} & \text { needle-penetration resistance } \\ q_{\mathrm{u}} & \text { unconfined compressive strength } \\ w & \text { water content } \\ w_{\mathrm{L}} & \text { liquid limit } \\ w_{\mathrm{n}} & \text { natural water content } \\ w_{\mathrm{P}} & \text { plastic limit } \\ \rho_{\mathrm{t}} & \text { wet density }\end{array}$

\section{Introduction}

The deep mixing method, a type of in situ admixture stabilisation technique using lime, cement or their mixture as a stabilising binder, was developed in Japan and Scandinavian countries in the 1970s (Broms, 1999; Broms and Boman, 1975, 1978, 1979; Holm, 1999; Okumura et al., 1972; Terashi et al., 1977, 1979, 1980, 1983). Subsequently, a considerable amount of research has been carried out on the characteristics of treated soil, the interaction of treated soil and surrounding soil, new binders development, the development of new execution machines and techniques, the establishment of design procedures and so on. The first international conference on the deep mixing method was co-organised by the Japanese Geotechnical Society (JGS) and the International Society for Soil Mechanics and Geotechnical Engineering (ISSMGE) TC-17 and held in 1996 in Tokyo. This conference was followed by a series of conferences/symposia in Stockholm in 1999, Helsinki in 2000, Tokyo in 2002, New Orleans in 2003, Stockholm in 2005, Okinawa in 2009, San Francisco in 2015 and Honolulu in 2017. The latest information on equipment, material properties, case records, design procedures, quality control and quality assurance has been updated and shared in those conferences. Moreover, technical manuals have been published in Japan (CDIT, 2014; PWRC, 2004), and Kitazume and Terashi (2013) summarised the state of the art in the deep mixing method, including design and execution methods.

The long-term changes in the properties of treated soil were investigated by several researchers in a laboratory (Kitazume et al., 2003; Nakamura and Kitazume, 2006; Terashi et al., 1983). They examined changes in unconfined compressive strength (UCS) and calcium content and showed that the strength increased or remained the same over the long term. These studies were also crucial in demonstrating that the 
surface of a treated soil, exposed to water or soil, deteriorated approximately by $10 \mathrm{~mm}$ in a curing year. Hayashi et al. (2003), Ikegami et al. (2003) and the Committee on Geocement (2014) investigated in situ treated soil cured for 17, 20 and 22 years, respectively. It was confirmed that the strength remained high, but the surface exposed to surrounding soil deteriorated. The deterioration depth reached $20-50 \mathrm{~mm}$ in nearly 20 years. These laboratory and field investigations thus showed that the strength of unexposed treated soil remained for at least 20 years, whereas that of exposed treated soil deteriorated.

In 1979, the authors' research group embedded two columns of in situ quicklime-treated soil in a soil tank. The soil wet density, water content, UCS and calcium content were measured 11 and 27 years later and compared with the initial data (Kitazume and Takahashi, 2008, 2009; Terashi and Kitazume, 1992). Following those investigations, the rest of the treated soil was cured in the soil tank again. The authors' research group decided to conduct a third investigation to examine long-term changes in properties with the help of the quicklime-treated soil cured for more than 37 years. The same tests, including UCS tests, were conducted to investigate the change in properties with time. Additionally, tests of $\mathrm{pH}$ and electrical conductivity (EC) were carried out in the third investigation aimed at examining the deterioration in properties from the surface exposed to soil for more than 37 years. In this paper, the construction conditions of the treated soil and the results of laboratory tests are described in order to discuss the long-term properties of in situ quicklime-treated soil.

\section{Execution of deep mixing and curing conditions}

\subsection{Site conditions and laboratory trial mix test}

The site was land reclaimed by dredged clayey soil in Fukuyama City, Hiroshima Prefecture, Japan; the ground was covered by sand or waste soil, including gravel. The land height was $+6 \cdot 1 \mathrm{~m}$ and the water table was $+5 \cdot 7 \mathrm{~m}$. The thickness of the covered soil was $2.3 \mathrm{~m}$ and the layer below it was soft dredged clayey soil of thickness $12 \cdot 8 \mathrm{~m}$, excluding a sand layer of +0.5 to $+1 \cdot 0 \mathrm{~m}$. The layer of $+3 \cdot 1$ to $-2.9 \mathrm{~m}$ was subjected to deep mixing and the clayey soil, excluding the contained sand layer, had the following soil properties: contents of clay and silt $=60 \%$ and $39 \%$; liquid limit, $w_{\mathrm{L}}=90 \%$; plastic limit, $w_{\mathrm{P}}=21 \%$; and natural water content, $w_{\mathrm{n}}=80 \%$. The organic matter content measured by the dichromic acid method was $3 \cdot 8 \%$ and the $\mathrm{pH}$ was approximately 8 .

Laboratory trial mix tests were conducted, before site execution, to obtain the fundamental properties of the treated soil. The UCS test used was almost the same as Japanese standards JSF T821-1990 and JSF T511-1990, established after these tests were carried out. The current Japanese standards JGS 0821-2009 and JGS 0511-2009 (JGS, 2015) were based on these prior standards. Figure 1 shows the relationship between the amount of quicklime and UCS. The UCS was enhanced by increasing the amount of binder, but the strength became stable with a certain amount of quicklime.

\subsection{Execution of deep mixing}

Deep mixing was implemented by the Deep Lime Mixing Association in December 1979. The major purpose of the execution was to examine the ability of a deep mixing machine, which at the time was not established then. Another objective was to understand the long-term properties of quicklime-treated soil. A land-type deep mixing machine mounting double-mixing shafts was used. The binder was granular quicklime. Figure 2 shows the mixing blades on the bottom of the mixing shaft. The method to supply quicklime was called 'withdrawal injection', wherein self-weight helped in

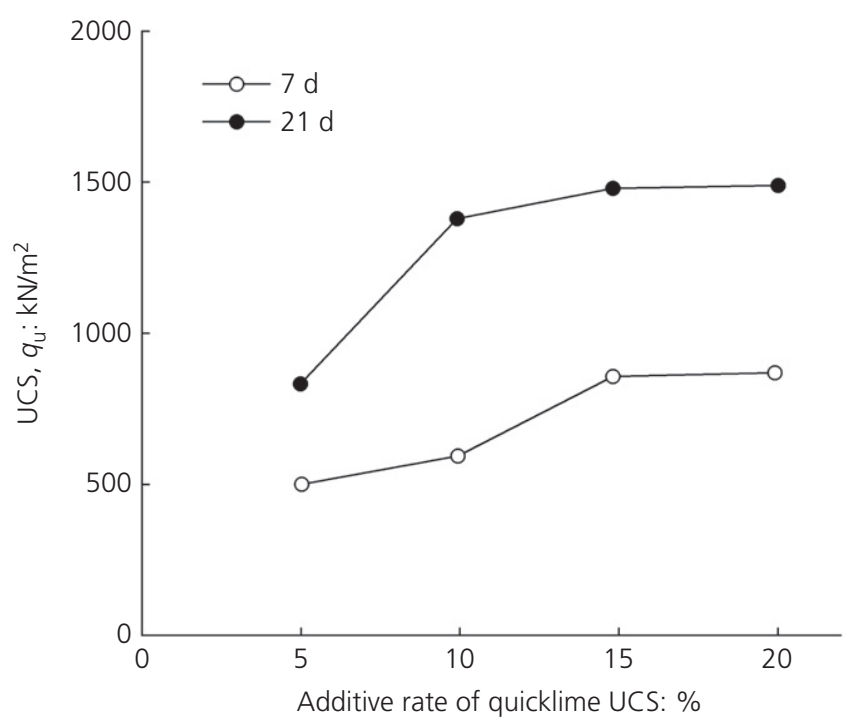

Figure 1. UCS and amount of quicklime

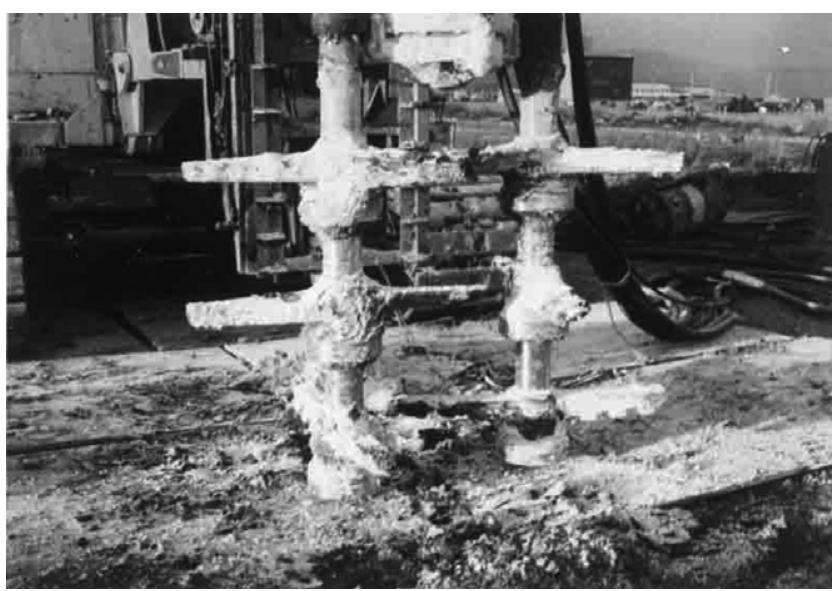

Figure 2. Tip of machine blade 


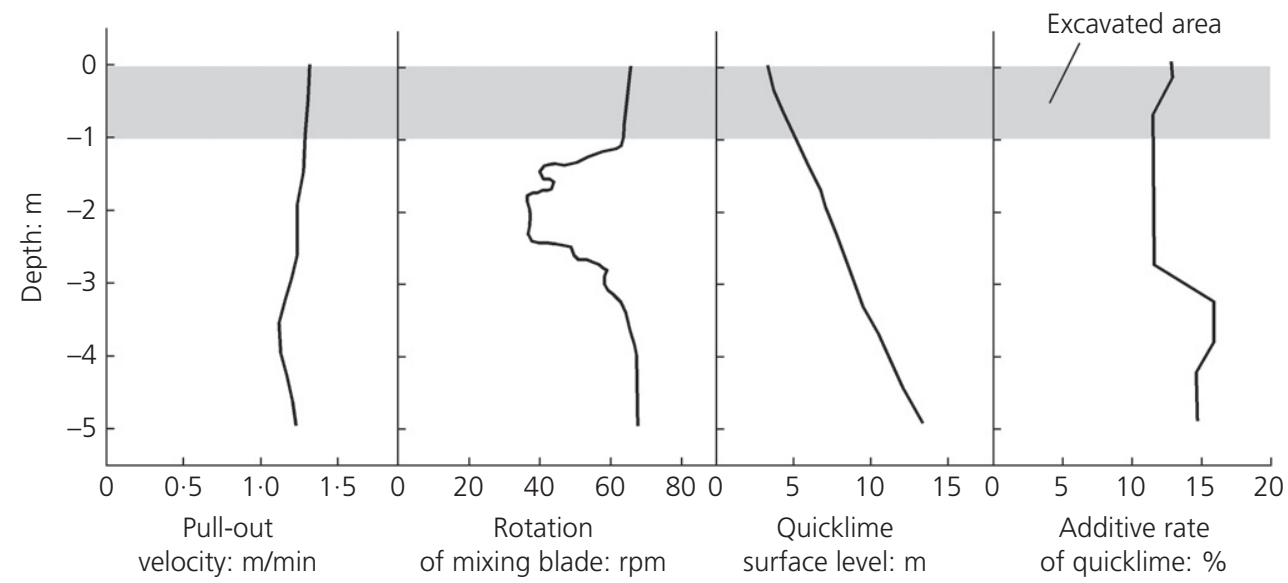

Figure 3. Execution data of deep mixing

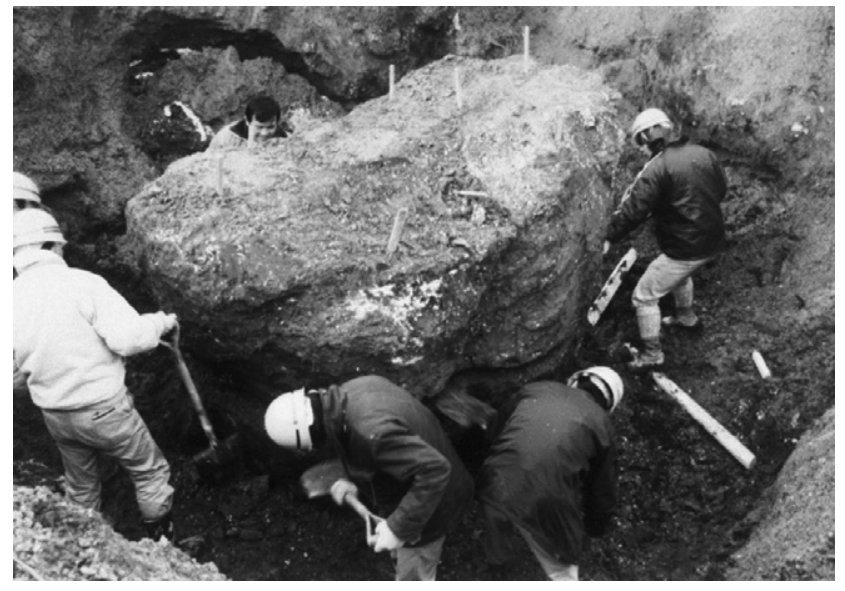

Figure 4. Treated soil after execution of deep mixing

penetrating the rotating blades and quicklime was discharged when the blades were lifted up. The lift-up speed, rotation number of blades and level of quicklime in a supply pipe were measured during the deep mixing execution. The level of quicklime in the supply pipe helped in calculating the amount of quicklime mixed into the soil. Figure 3 summarises the execution data. The treated soil, with a depth of 0 to $-1 \mathrm{~m}$, was used for long-term curing. The quicklime content was $11-13 \%$. The calcium content of the quicklime was more than $95 \%$, the particle size was $2 \cdot 5-10 \cdot 0 \mathrm{~mm}$ and the activity coefficients of $4 \mathrm{~N}$ hydrochloric acid were 15-35\%/1 min and $70-85 \% / 10 \mathrm{~min}$.

\subsection{Curing conditions in soil tank}

The deep mixing machine mounting double mixing shafts produced a glass-like cross-section, as shown in Figure 4. The treated soil was extracted after 2 months. As the block was large, it was divided into two blocks, named blocks A and B, and transported to the Port and Airport Research Institute (see Figure 5). The soil tank for curing was a concrete

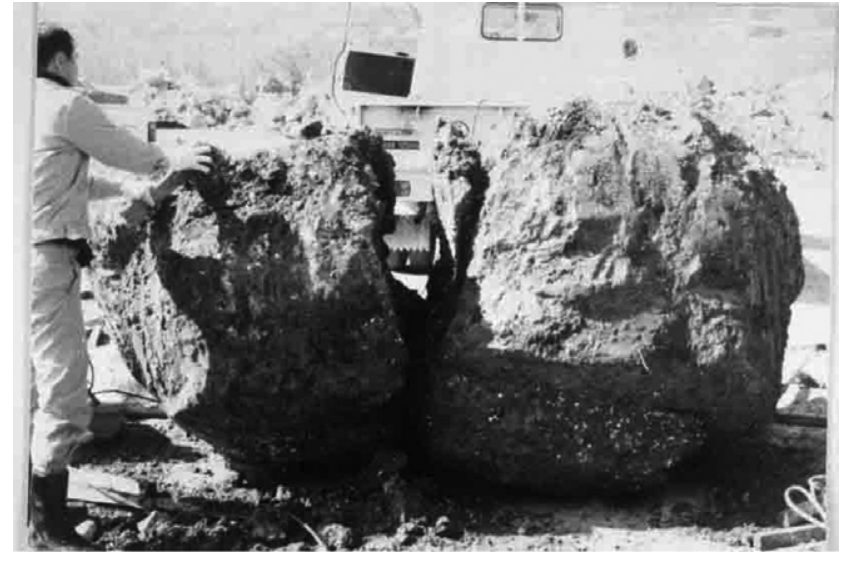

Figure 5. Divided treated soil for curing

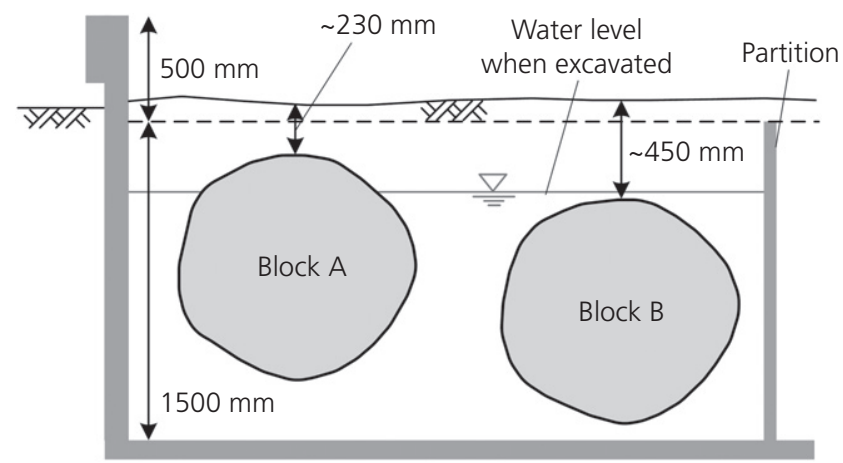

Figure 6. Position of treated soil blocks in soil tank

cylindrical container with a diameter of $7 \mathrm{~m}$ and depth of $2 \mathrm{~m}$. The treated soil was embedded in untreated soil consisting of silt and clay. Figure 6 shows the positions of the treated soil blocks. The soil tank had no roof to prevent the entry of rain; therefore, the water level could not be controlled during the curing time. However, the water level was around 
Table 1. Sequence of events

\begin{tabular}{llll} 
Event & Timing & Elapsed time & Notes \\
\hline Execution of deep mixing & December 1979 & $0 \mathrm{~d}$ & In the field \\
Excavation and in situ testing & February 1980 & $63 \mathrm{~d}$ & In the field \\
Splitting and transport & February 1980 & $84 \mathrm{~d}$ & In the field \\
Embedding & March 1980 & $90 \mathrm{~d}$ & In the institute \\
First investigation & March 1991 & 11 years and 3 months & \\
Second investigation & January 2007 & 27 years and 1 month & 37 years and 1 month \\
Third investigation & January 2017 & S7 &
\end{tabular}

the top of the treated soil in every investigation. The soil tank was not full of water, even during the rainy season in Japan. This indicated that the upper and lower parts of the soil maintained unsaturated and saturated conditions, respectively. Table 1 lists the sequence of events in the project. The first, second and third investigations were carried out during 1991, 2007 and 2017, respectively.

Undisturbed samples were extracted from the surface of the treated soil under blocks A and B in the field. Table 2 shows the $64 \mathrm{~d}$ UCS. The appended figure shows the position of nine samples. The specimen had a diameter of $50 \mathrm{~mm}$ and a height of $100 \mathrm{~mm}$. The water content and wet density were not dispersed and the UCS ranged between 726 and $1352 \mathrm{kN} / \mathrm{m}^{2}$ (with an average of $1002 \mathrm{kN} / \mathrm{m}^{2}$ ). The coefficient of variation $(\mathrm{CoV})$ was $20.0 \%$, which is commonly observed with regard to UCS. The $7 \mathrm{~d}$ and $21 \mathrm{~d}$ strengths of treated soil mixed and cured in a laboratory were approximately 700 and $1400 \mathrm{kN} / \mathrm{m}^{2}$, respectively, based on laboratory trial mix tests. According to Hayashi et al. (2003), strength increases in proportion to the logarithm of the curing period. Considering this relation, the $64 \mathrm{~d}$ strength in the laboratory was estimated to be approximately $2100 \mathrm{kN} / \mathrm{m}^{2}$. As the strength measured in the field was much smaller than that in the laboratory, the average strength of $1002 \mathrm{kN} / \mathrm{m}^{2}$ measured in the field was reasonable.

\section{Investigation methods}

\subsection{First investigation (11 years later)}

\subsubsection{Excavation}

On March 1991, 11 years after the deep mixing execution, a first investigation was implemented on block B. Weeds that grew on the ground surface were manually removed and it was ensured that their roots had not reached the treated soil. The soil surrounding the treated soil was excavated manually using a crawler excavator; the treated soil was hoisted with the help of a nylon sling and a compact crane. After the soil attached to the treated soil was removed, a visual survey of the surface was conducted by photographing and sketching.

\subsubsection{Boring}

After the treated soil was placed and fixed in the soil tank, boring was conducted from the temporary stage above the
Table 2. Properties of in situ quicklime-treated soil

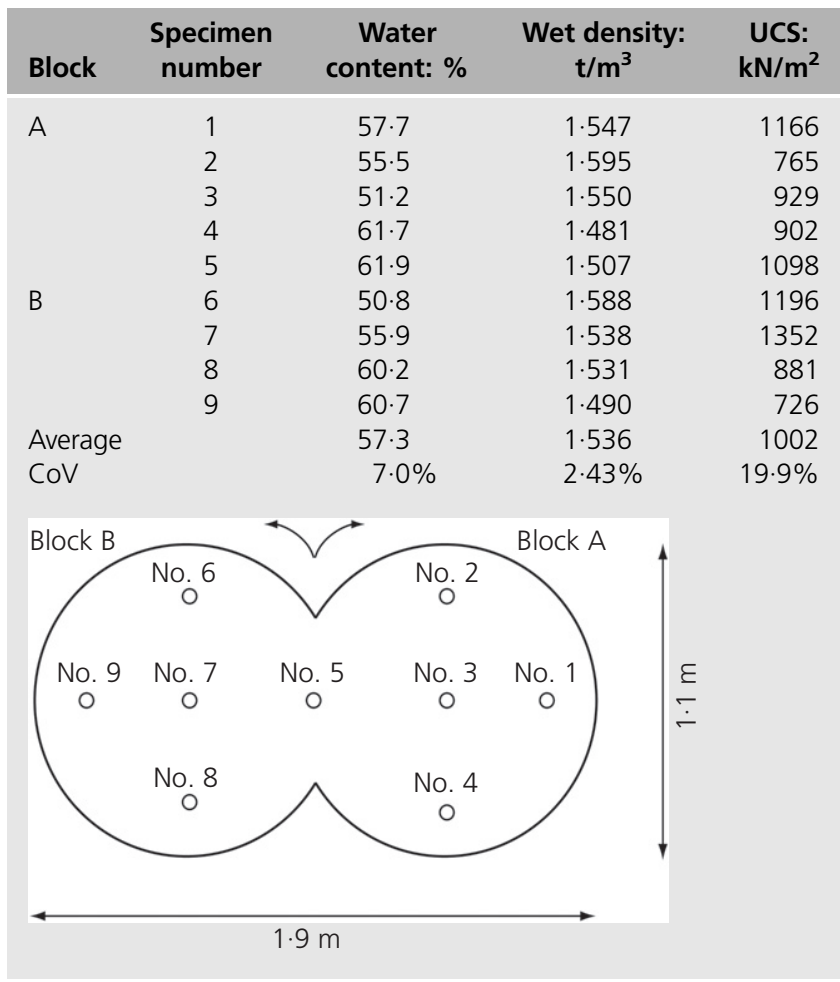

tank (see Figure 7). A hand-feed rotary-type machine was used. Many fragments and cracks unfortunately occurred in the treated soil during sampling due to its brittleness, although it was bored with extreme caution. The outer and inner diameters of the soil sampler, a core pack tube, were $86 \mathrm{~mm}$ and $68 \mathrm{~mm}$, respectively. Figure 8 shows the plane positions and distances of boreholes; the number indicates the order of boring. The boreholes drilled in the first investigation were numbers $1-8$ in block $\mathrm{B}$. The boring cores were transported to the laboratory in a wet condition, wrapped in transparent film and cotton cloth. Figure 9(a) shows block B before it was covered with soil.

\subsubsection{Laboratory tests}

Laboratory tests, including UCS tests, wet density tests, water content tests and calcium content tests, were carried out based on Japanese standards JSF T511-1990, JSF T191-1990 and JSF T121-1990, respectively. These standards were inherited by 
Ground Improvement

Volume 171 Issue GI3
Thirty-seven-year investigation of quicklime-treated soil produced by deep mixing method

Takahashi, Morikawa, Fujii and Kitazume

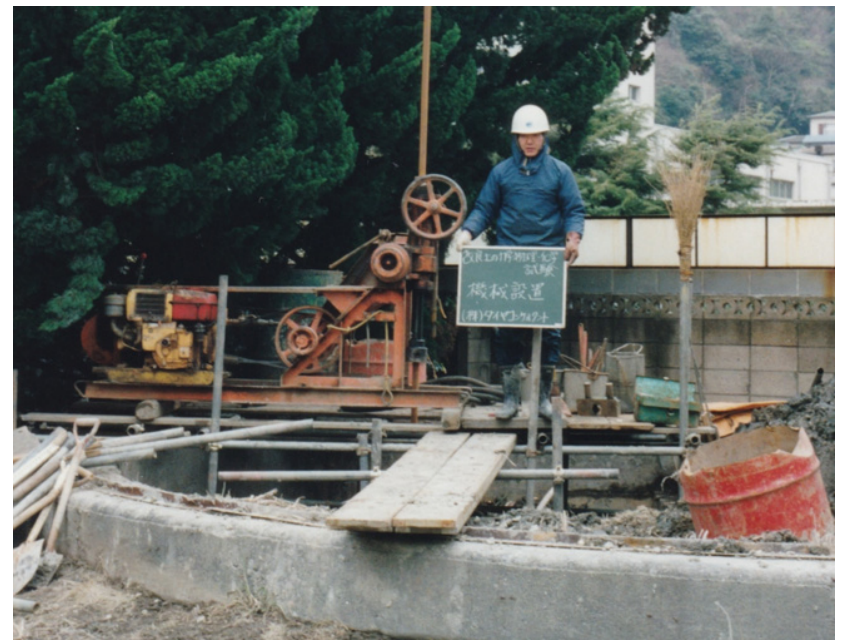

Figure 7. Temporary stage over the tank for boring
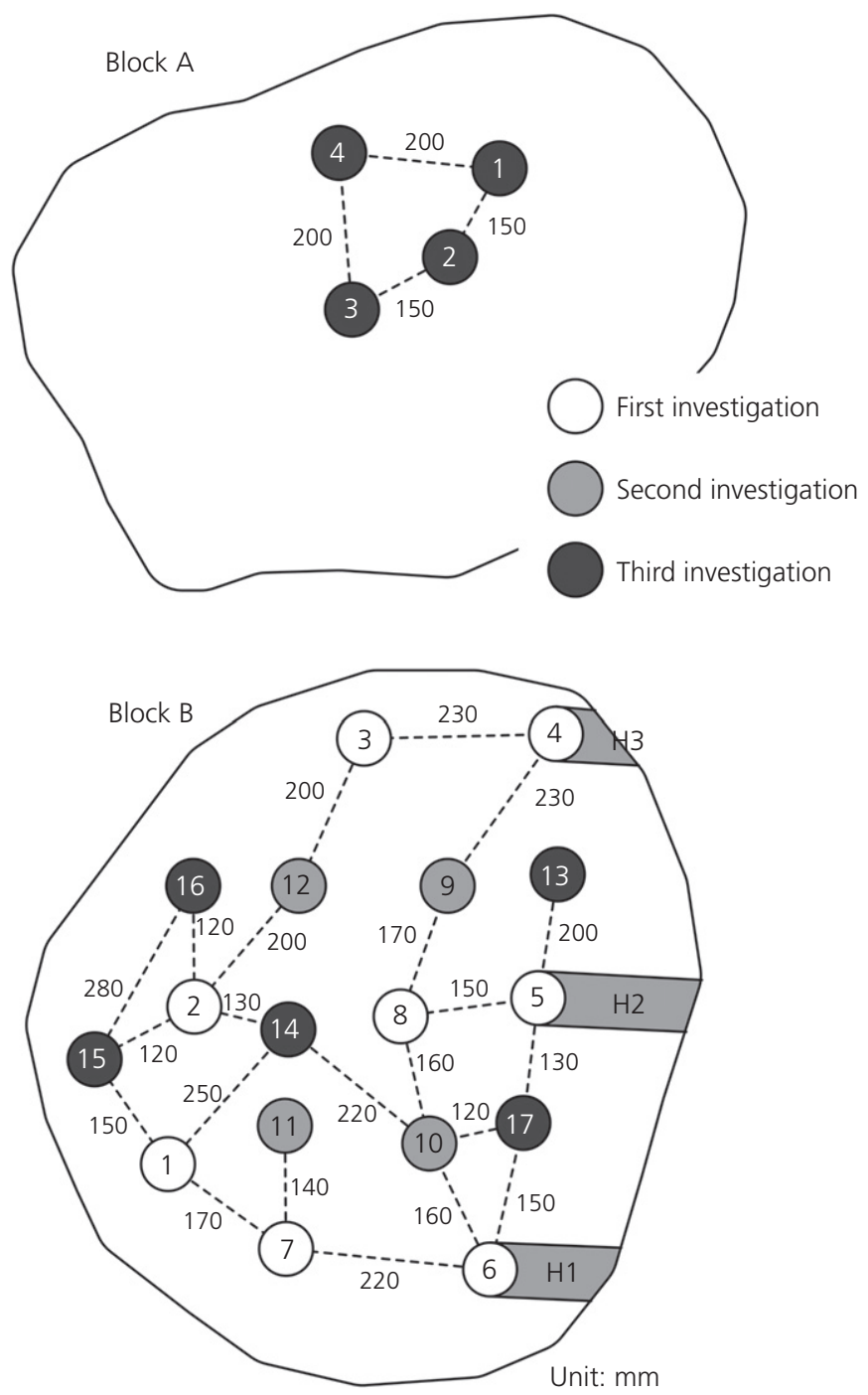

Figure 8. Plane positions of boreholes

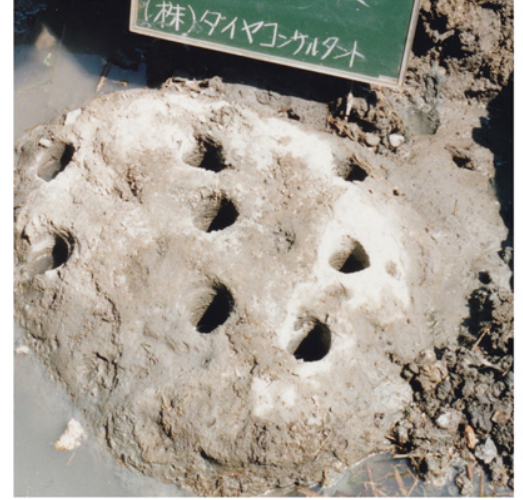

(a)

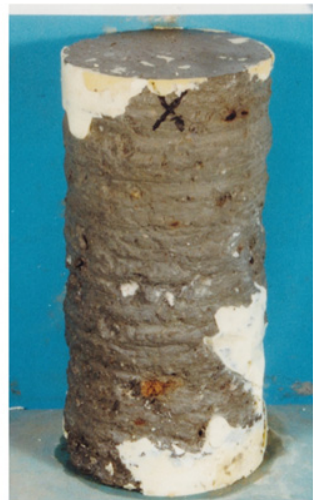

(b)
Figure 9. Treated soil in first investigation. (a) Surface of treated soil. (b) Test specimen

the current Japanese standards JGS 0511-2009, JGS 0191-2009 and JGS 0121-2009 (JGS, 2015). The calcium content was measured by the method proposed by concrete committee F-18 of the Japan Cement Association (JCA, 1967). This method estimates the calcium content using dilute hydrochloric acid. The number of specimens for UCS tests was 24, and the specimens were taken from the upper, middle and lower parts of the boring cores.

At first, an attempt was made to prepare a certain diameter of specimen, $50 \mathrm{~mm}$, for UCS tests; however, since the cores were largely hard, it was difficult to trim the cores neatly. Accordingly, only conspicuous roughness was removed by using a straight knife and trimmer. The diameters were thus $60-68 \mathrm{~mm}$. The top and bottom surfaces were straightened using a surface grinding machine. Fragments and cracks caused difficulty in preparing specimens with an aspect ratio of 2 (height to diameter); the heights were $70-140 \mathrm{~mm}$. In this paper, 14 specimens with a large aspect ratio of more than 1.8 are used in the discussion on UCS tests. Figure 9(b) shows an example of the specimen, in which conspicuous chips and voids were filled with hard plaster. An unconfined compressive test machine compressed the specimen with a constant strain rate of $1 \% / \mathrm{min}$.

\subsection{Second investigation (27 years later)}

\subsubsection{Excavation}

On January 2007, 27 years after the execution of deep mixing, the second investigation was conducted on block B. Weeds growing on the ground surface were removed. The surrounding soil was excavated manually using a crawler excavator. The treated soil was not taken outside because a visual survey was not conducted. However, the treated soil was hoisted to tilt it up to $45^{\circ}$. Tilting was needed in order to take horizontal cores from the side of the treated soil. Clear boreholes made in the first investigation were found and the covering soil had entered some of the boreholes. 


\subsubsection{Boring}

Boring was conducted from the temporary stage; the machine used for boring was a hand-feed and rotary type. This was the same type of machine as used in the first investigation, but several improvements were made to the machine and sampler for the sake of collecting high-quality cores. The machine rotated a sampler at a speed of $900 \mathrm{r} / \mathrm{min}$ and diamond bits were arranged on the tip of the sampler. Additionally, the vibration due to the gears and the gap between the centres of the sampler and the motor shaft were reduced by directly attaching the sampler to the motor shaft. The outer and inner diameters of the core pack tube were 86 and $65 \mathrm{~mm}$, respectively.

The boreholes drilled in the second investigation were numbers 9-12 and $\mathrm{H} 1-\mathrm{H} 3$ in block B shown in Figure 8. Numbers 9-12 and H1-H3 were vertical and horizontal borings, respectively. Horizontal boring was implemented by tilting the block, as already mentioned and these boreholes reached boreholes 4-6 drilled in the first investigation. Boring cores were transported to the laboratory in a wet condition, wrapped in transparent film and cotton cloth. Figure 10(a) shows a photograph of block B.

\subsubsection{Laboratory tests}

UCS tests, wet density tests, water content tests and calcium content tests were carried out based on the standards followed by the current Japanese standards JGS 0511-2009, JGS 01912009 and JGS 0121-2009 (JGS, 2015). The calcium content was measured by the previously mentioned method (JCA, 1967). The number of specimens was 12 and they were taken from the upper, middle and lower parts of the boring cores. The side face was not trimmed; the diameter was $65 \mathrm{~mm}$ and was not scattered due to the high-quality boring in the second investigation. The boring cores for UCS tests were cut every $130 \mathrm{~mm}$, adjusting the aspect ratio to 2 . Figure 10(b) shows an example of the specimen. The strain rate of the UCS test was set to $0 \cdot 5 \% / \mathrm{min}$.

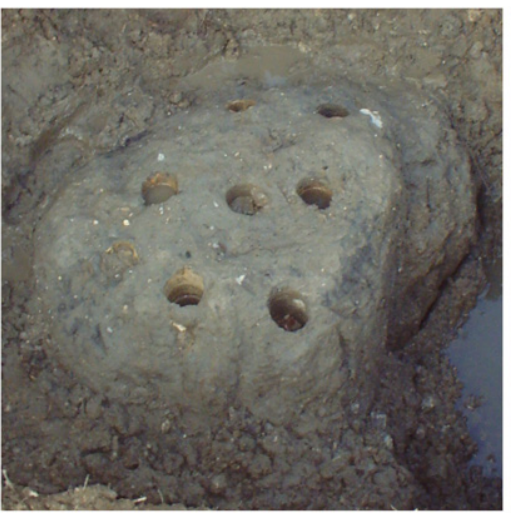

(a)

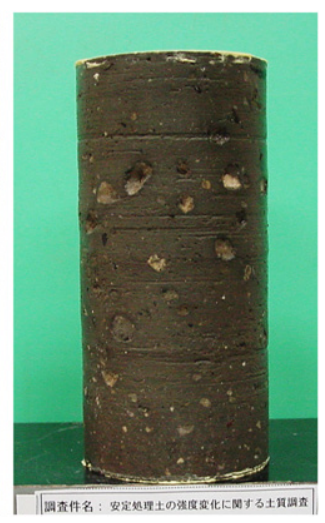

(b)
Figure 10. Treated soil in second investigation. (a) Surface of treated soil. (b) Test specimen
Needle-penetration tests, water content tests and calcium content tests were implemented, against the surface of the cores, to investigate the deterioration of treated soil exposed to the surrounding soil. A needle-penetration test estimates the strength of soft rock and this is one of the miniature penetration tests (JSCE, 1991). Kitazume et al. (2003) revealed that this test enabled the measurement of deterioration depth from the surface. In the test, a sewing needle was penetrated into the treated soil at a constant rate and the resistance force was measured. The relationship between the resistance force and displacement clearly changed at the deterioration depth. The diameter of the needle used in this test was $0.84 \mathrm{~mm}$ and the penetration rate was $3 \mathrm{~mm} / \mathrm{min}$. In addition to the needlepenetration tests, water and calcium contents were measured in the treated soil.

\subsection{Third investigation (37 years later)}

\subsubsection{Excavation}

A third investigation was conducted on blocks A and B in January 2017, 37 years later after the execution of deep mixing. There were two reasons for utilising blocks A and B in this investigation. First, the many boreholes in block B made it difficult to conduct new boring. Second, the test results in block A will help sustain the continuity of this project, when block B will be used up in the future. As before, weeds on the ground surface were removed and the surrounding soil was excavated manually. Clear boreholes made in the first and second investigations were found and the covering soil penetrated some of the boreholes.

\subsubsection{Boring}

The boring method was the same as in the second investigation. The boreholes drilled in the third investigation were numbers $1-4$ in block $A$ and numbers $13-17$ in block B, as shown in Figure 8. Boring cores were transported to the laboratory in a wet condition, wrapped in transparent film. Figure 11(a) shows a photograph of blocks A and B.

\subsubsection{Laboratory tests}

UCS tests, wet density tests, water content tests and calcium content tests were carried out based on the current Japanese standards JGS 0511-2009, JGS 0191-2009 and JGS 0121-2009 (JGS, 2015). The calcium content was measured by the previously mentioned method (JCA, 1967). 24 specimens were taken from the upper, middle and lower parts of boring cores. The side face was not trimmed, and the diameter and height of the specimens for UCS tests were 65 and $130 \mathrm{~mm}$, respectively. Two of the 24 specimens had abnormal values and they were thus excluded from the following discussion on UCS tests. Figure 11(b) shows an example specimen. The strain rate of the UCS test was set to $0 \cdot 5 \% / \mathrm{min}$.

Needle-penetration tests, water content tests and calcium content tests were also implemented against the cores' surface. 
The test methods were the same as in the second investigation. In the third investigation, $\mathrm{pH}$ and $\mathrm{EC}$ were additionally measured to examine the level of deterioration by using a suspension mixed with distilled water and crushed treated soil. Calcium contained in quicklime ionises in water, producing an alkali atmosphere. High $\mathrm{pH}$ and EC would help in detecting remaining calcium.

\section{Change in properties with time}

\subsection{Visual survey}

Figure 12 shows block B observed in the first investigation, 11 years after the deep mixing execution. The cross-sectional shape of the treated soil was spectacle shaped, as shown in Figure 4; however, the shape of the embedded treated soil was a distorted globe due to excavation and splitting, as shown in Figure 5. The treated soil taken out had the same shape. The surface of the treated soil was rugged; the colour was charcoal grey including some white parts showing unreacted quicklime.

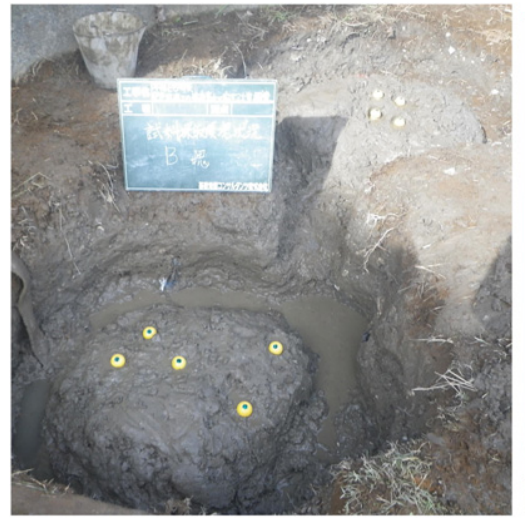

(a)

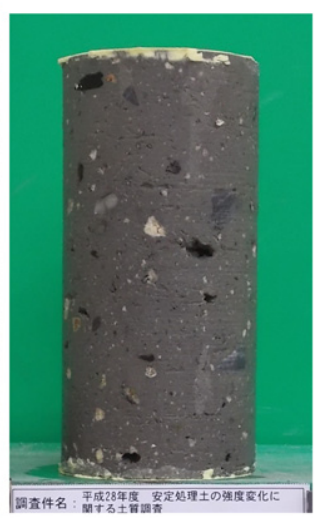

(b)
Figure 11. Treated soil in third investigation. (a) Surface of treated soil. (b) Test specimen

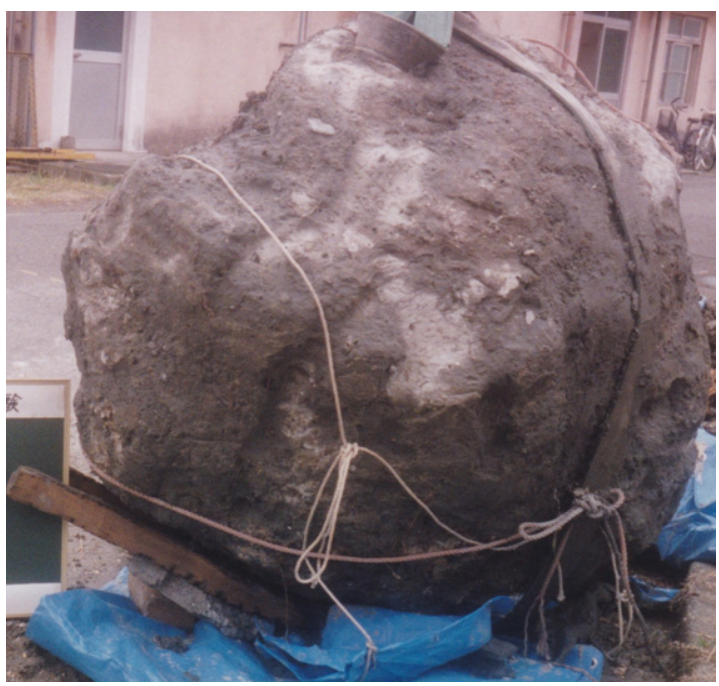

Figure 12. Block B in first investigation
In the first investigation, many fragments and cracks, generated by boring executions, were observed in the cores, whereas few fragments and cracks were found in the second and third investigations. The rock quality designation (RQD) method, which is often used for rock cores, was adopted to assess the quality of the cores. The RQD value is the ratio of non-cracked and total lengths of a core. The non-cracked length is calculated by summing the lengths of more than $100 \mathrm{~mm}$ long specimens that have no crack. Table 3 lists the RQD values. The RQDs in the first investigation ranged from $47 \%$ to $88 \%$, with the average being $76 \%$. On the other hand, the values in the second and third investigations were almost $100 \%$, showing that the second and third borings were of high quality.

\subsection{Physical properties}

The physical properties of the treated soil inside the blocks, not influenced by the surrounding soil, were investigated and are summarised in Table 4 and Figure 13. The table and figure include mechanical and chemical properties mentioned in the following sections. Figure 13 shows that the wet density was almost uniform in the depth direction. The average was $1.527-1.537 \mathrm{t} / \mathrm{m}^{3}$ and the $\mathrm{CoV}$ was low, as shown in Table 4 . Figure 14(a) shows the wet density for each year, indicating that a change over time could not be observed.

The water content increased slightly in the depth direction. Since this increase was small, any change in wet density would be invisible in the figure. The reason for the small change in

Table 3. RQD values

\begin{tabular}{|c|c|c|c|c|}
\hline & $\begin{array}{l}\text { Borehole } \\
\text { number }\end{array}$ & $\begin{array}{c}\text { Length } \\
\text { of core: } \\
\text { mm }\end{array}$ & $\begin{array}{c}\text { Effective } \\
\text { length: } \\
\mathrm{mm}\end{array}$ & RQD: \% \\
\hline \multirow[t]{9}{*}{ First investigation } & 1 & 1030 & 910 & $88 \cdot 3$ \\
\hline & 2 & 1010 & 890 & $88 \cdot 1$ \\
\hline & 3 & 840 & 680 & $81 \cdot 0$ \\
\hline & 4 & 700 & 330 & $47 \cdot 1$ \\
\hline & 5 & 950 & 790 & $83 \cdot 2$ \\
\hline & 6 & 610 & 470 & $77 \cdot 0$ \\
\hline & 7 & 900 & 730 & $81 \cdot 1$ \\
\hline & 8 & 950 & 590 & $62 \cdot 1$ \\
\hline & Average & & & $76 \cdot 0$ \\
\hline \multirow[t]{5}{*}{ Second investigation } & 9 & 1010 & 1010 & $100 \cdot 0$ \\
\hline & 10 & 970 & 970 & $100 \cdot 0$ \\
\hline & 11 & 1080 & 1080 & $100 \cdot 0$ \\
\hline & 12 & 1080 & 1080 & $100 \cdot 0$ \\
\hline & Average & & & $100 \cdot 0$ \\
\hline \multirow[t]{10}{*}{ Third investigation } & A1 & 1110 & 1110 & $100 \cdot 0$ \\
\hline & A2 & 1070 & 1070 & $100 \cdot 0$ \\
\hline & A3 & 1070 & 880 & $82 \cdot 2$ \\
\hline & A4 & 1100 & 1100 & $100 \cdot 0$ \\
\hline & B13 & 310 & 310 & $100 \cdot 0$ \\
\hline & B14 & 1030 & 1030 & $100 \cdot 0$ \\
\hline & B15 & 1010 & 1010 & $100 \cdot 0$ \\
\hline & B16 & 970 & 970 & $100 \cdot 0$ \\
\hline & B17 & 700 & 630 & $90 \cdot 0$ \\
\hline & Average & & & $96 \cdot 9$ \\
\hline
\end{tabular}


Table 4. List of test results

\begin{tabular}{|c|c|c|c|c|c|c|}
\hline Test item & Curing period & Number of specimens & Maximum & Minimum & Average & CoV: $\%$ \\
\hline \multirow[t]{5}{*}{ Wet density: $t / \mathrm{m}^{3}$} & $64 d$ & 9 & 1.595 & 1.481 & 1.536 & $2 \cdot 4$ \\
\hline & 11 years & 24 & 1.579 & 1.486 & 1.527 & $2 \cdot 2$ \\
\hline & 27 years & 12 & $1 \cdot 622$ & $1 \cdot 505$ & $1 \cdot 537$ & 1.9 \\
\hline & 37 years (block A) & 12 & 1.603 & $1 \cdot 504$ & 1.536 & 1.5 \\
\hline & 37 years (block B) & 12 & $1 \cdot 577$ & 1.484 & $1 \cdot 536$ & $1 \cdot 7$ \\
\hline \multirow[t]{5}{*}{ Water content: \% } & $64 d$ & 9 & $61 \cdot 9$ & $50 \cdot 8$ & $57 \cdot 3$ & $7 \cdot 0$ \\
\hline & 11 years & 24 & $70 \cdot 8$ & $52 \cdot 2$ & $61 \cdot 9$ & $7 \cdot 3$ \\
\hline & 27 years & 12 & $64 \cdot 1$ & $34 \cdot 5$ & $51 \cdot 5$ & $16 \cdot 1$ \\
\hline & 37 years (block $A)$ & 12 & $69 \cdot 1$ & $58 \cdot 5$ & $63 \cdot 6$ & $4 \cdot 8$ \\
\hline & 37 years (block B) & 12 & $75 \cdot 8$ & $57 \cdot 6$ & $65 \cdot 2$ & $6 \cdot 6$ \\
\hline \multirow[t]{5}{*}{ UCS: kN/m² } & $64 \mathrm{~d}$ & 9 & 1352 & 726 & 1002 & $19 \cdot 9$ \\
\hline & 11 years & 14 & 4814 & 2686 & 3641 & $18 \cdot 8$ \\
\hline & 27 years & 12 & 5326 & 2507 & 3538 & $23 \cdot 8$ \\
\hline & 37 years (block $A)$ & 11 & 4963 & 2734 & 3629 & $21 \cdot 7$ \\
\hline & 37 years (block B) & 11 & 4716 & 2338 & 3357 & $19 \cdot 1$ \\
\hline \multirow[t]{4}{*}{ Deformation modulus: $\mathrm{MN} / \mathrm{m}^{2}$} & 11 years & 14 & 2000 & 624 & 1494 & $23 \cdot 7$ \\
\hline & 27 years & 12 & 1921 & 1132 & 1416 & $18 \cdot 0$ \\
\hline & 37 years (block $A)$ & 11 & 1998 & 502 & 996 & $39 \cdot 7$ \\
\hline & 37 years (block B) & 11 & 1440 & 721 & 993 & $25 \cdot 6$ \\
\hline \multirow{4}{*}{ Calcium content: \% } & 11 years & 24 & 18 & 8 & $14 \cdot 3$ & $18 \cdot 9$ \\
\hline & 27 years & 12 & 12 & 4 & $9 \cdot 1$ & $25 \cdot 6$ \\
\hline & 37 years (block A) & 12 & 20 & 13 & $15 \cdot 8$ & $16 \cdot 0$ \\
\hline & 37 years (block B) & 12 & 20 & 10 & $14 \cdot 9$ & $19 \cdot 6$ \\
\hline \multirow[t]{2}{*}{$\mathrm{pH}$} & 37 years (block $A$ ) & 12 & $12 \cdot 3$ & $11 \cdot 2$ & $11 \cdot 7$ & $2 \cdot 8$ \\
\hline & 37 years (block B) & 12 & $11 \cdot 7$ & $11 \cdot 1$ & $11 \cdot 4$ & 1.6 \\
\hline \multirow[t]{2}{*}{$\mathrm{EC}: \mathrm{S} / \mathrm{m}$} & 37 years (block $A)$ & 12 & 0.92 & 0.33 & 0.52 & $31 \cdot 7$ \\
\hline & 37 years (block B) & 12 & 0.39 & $0 \cdot 19$ & 0.31 & $21 \cdot 7$ \\
\hline
\end{tabular}

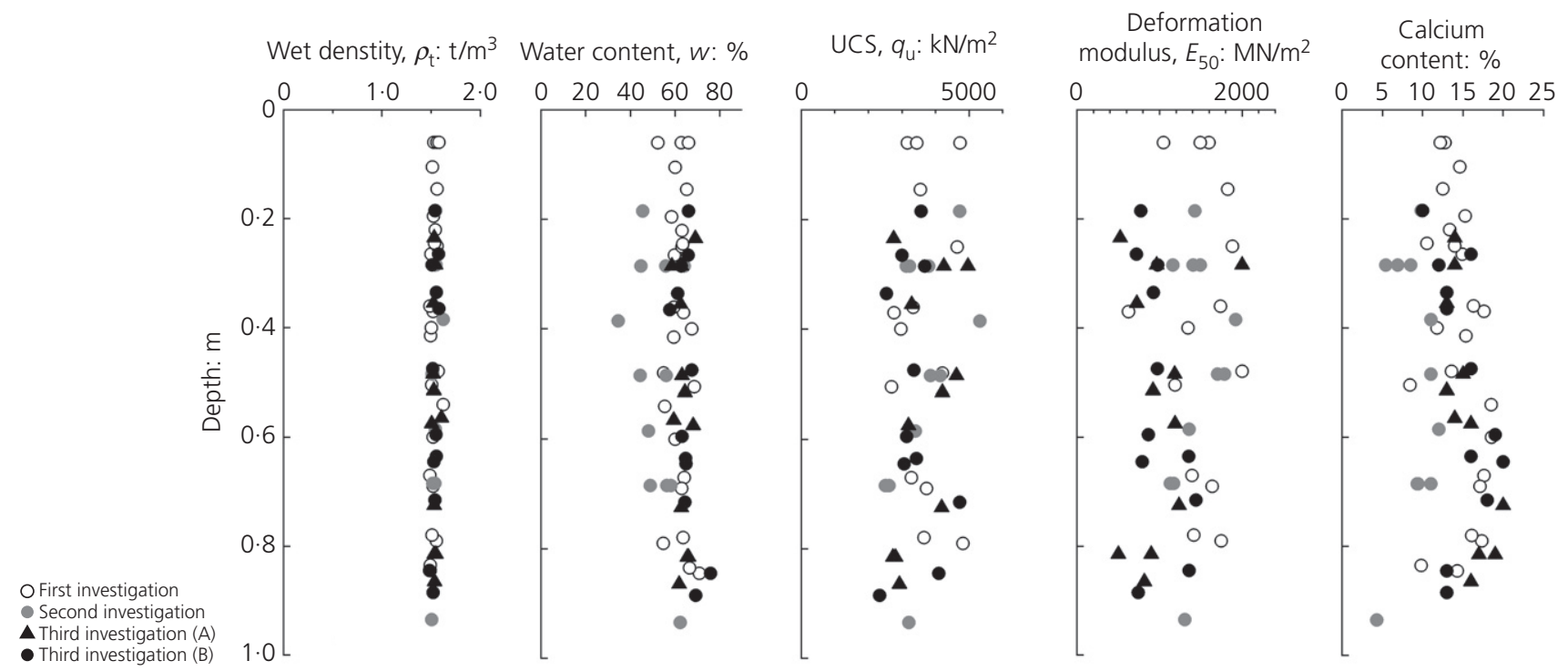

Figure 13. Depth distribution of measurements

water content was not analysed, although it can be assumed that the unsaturated condition of the upper part affected it. Figure 14(b) shows the water content for each year. It was especially low, with an average of $51.5 \%$, in the second investigation whereas it was $57 \cdot 3-65 \cdot 2 \%$ in the other investigations. It was difficult to consider that the treated soil dried as a whole because deterioration due to alternating immersion was not observed in the third investigation. In addition, the specimen in the second investigation contained a small amount of calcium; therefore, the possibility that the quicklime used up water is low. Consequently, it is reasonable to consider that the water content of the specimen was 


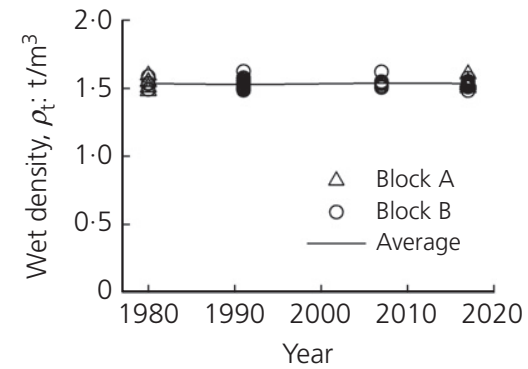

(a)

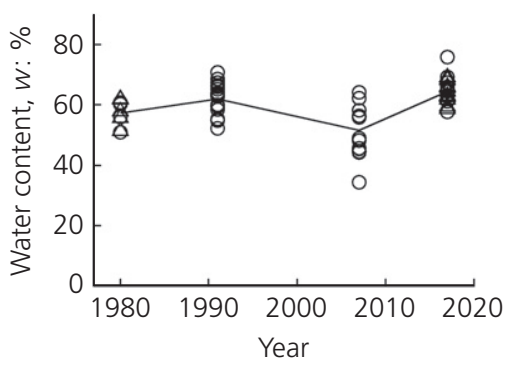

(b)

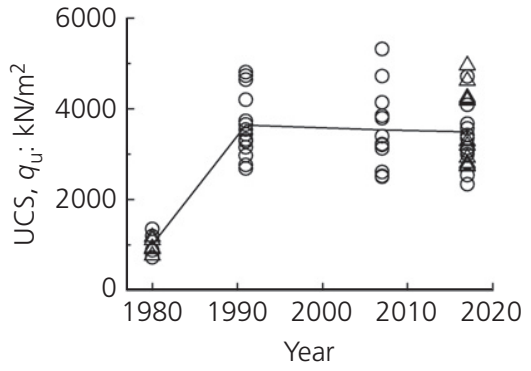

(c)

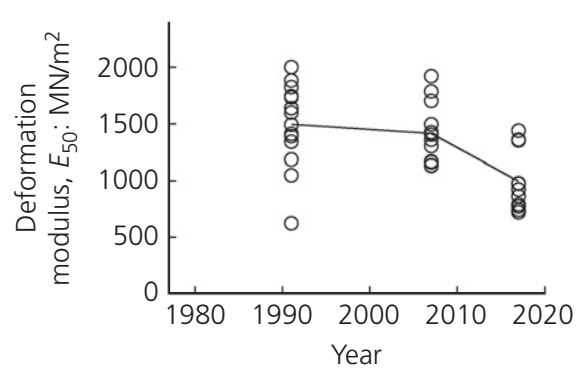

(d)

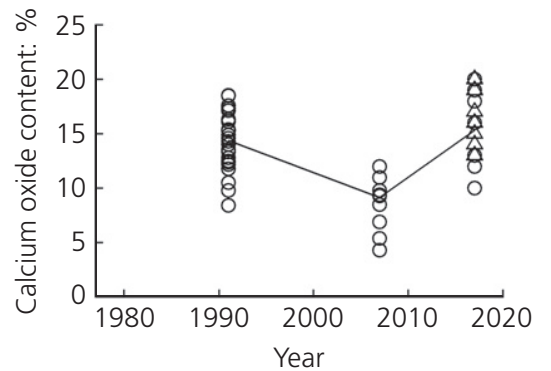

(e)

Figure 14. Change in properties over time

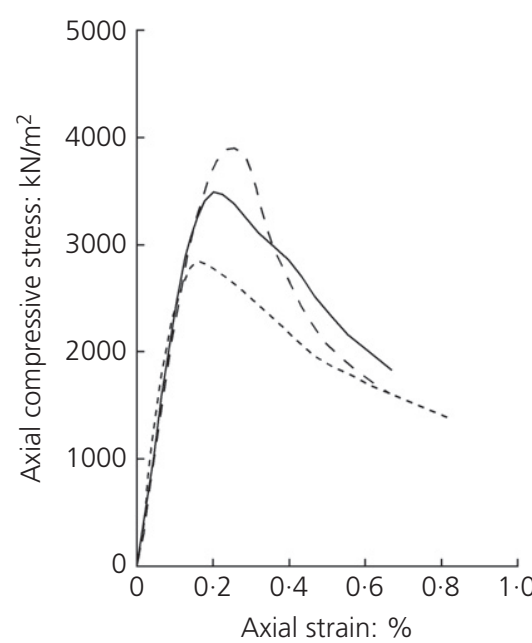

(a)

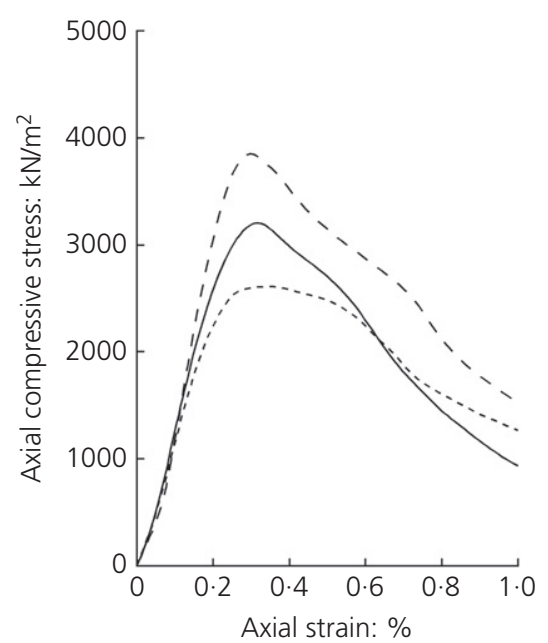

(b)

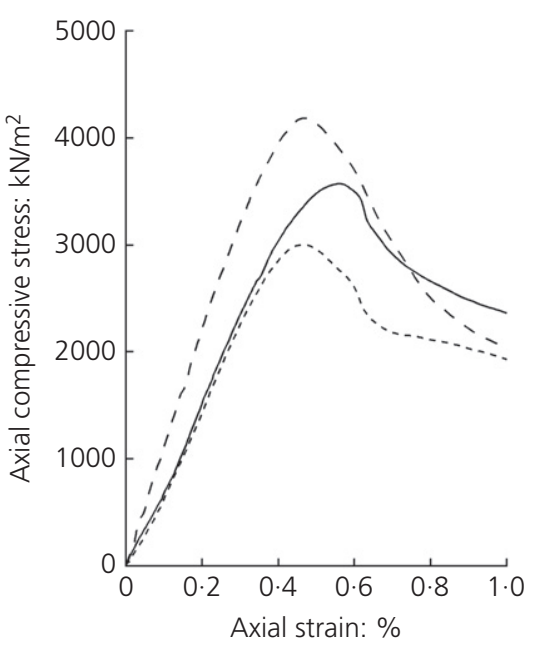

(c)

Figure 15. Example of stress-strain curves of UCS test specimens: (a) first investigation; (b) second investigation; (c) third investigation

incidentally low in the second investigation. This is supported by the large $\mathrm{CoV}$.

\subsection{Mechanical properties}

\subsubsection{UCS}

In the first investigation, approximately half of the UCS test specimens had a low aspect ratio $(<1 \cdot 8)$, as mentioned previously. These specimens are excluded from the following discussion because the strength of a specimen with a small aspect ratio tends to be large. Figure 15 shows examples of stress-strain curves in UCS tests. The specimens collapsed by brittle fracture. Table 4 and Figure 13 summarise the UCS, $q_{\mathrm{u}}$. The figure shows that the UCS was almost uniform in the depth direction. Figure 14(c) shows the UCS for each year. The average UCS largely increased from 1002 to $3641 \mathrm{kN} / \mathrm{m}^{2}$, measured $64 \mathrm{~d}$ and 11 years after the execution, respectively. Afterwards, it almost remained constant from the first investigation to the third. A large change with time could not be observed in the CoVs of $18 \cdot 8-23 \cdot 8 \%$. It can thus be said that the strength of the treated soil remained for 37 years and quicklime treatment is effective for a long period. 


\subsubsection{Deformation modulus}

Table 4 and Figure 13 also show the secant deformation modulus, $E_{50}$, obtained in UCS tests. The deformation modulus was largely scattered. Figure 14(d) indicates the deformation modulus for each year. It does not include the $64 \mathrm{~d}$ deformation modulus since this was not recorded. As the strength in the first investigation was more than three times larger than that measured on day 64, the average deformation modulus of $1494 \mathrm{MN} / \mathrm{m}^{2}$ in the first investigation would be much larger than that on day 64. On the other hand, the deformation modulus slightly decreased with the curing time.

Figure 16 shows the relationship between the deformation modulus $E_{50}$ and UCS, $q_{\mathrm{u}}$. It is well known that these parameters have a linear relationship (Kitazume and Terashi, 2013). The linear relationship can be seen in the figure, although the plots are scattered. The lines represent regressions based on the data for each investigation. It can be observed that the slopes of the third investigation (280 and 296) were smaller than those of the first and second investigations (409 and 391). A 26 year curing resulted in a decrease in treated soil stiffness by $28-32 \%$. This might be a sign of a change in soil structure and the deformation modulus must be observed carefully in a further investigation.

\subsection{Chemical properties}

\subsubsection{Calcium content}

Table 4 and Figure 13 summarise the calcium content, estimated by calcium oxide $(\mathrm{CaO})$ content, obtained in the UCS test specimens. The calcium content slightly increased in the depth direction although the data were scattered. Figure 14(e) shows the calcium content for each year; it was especially low in the second investigation. The average was $9 \cdot 1 \%$ in the second investigation and $14 \cdot 3-15.8 \%$ in the other investigations. The emission of calcium was suspected immediately after the second investigation; however, this could not be confirmed because the

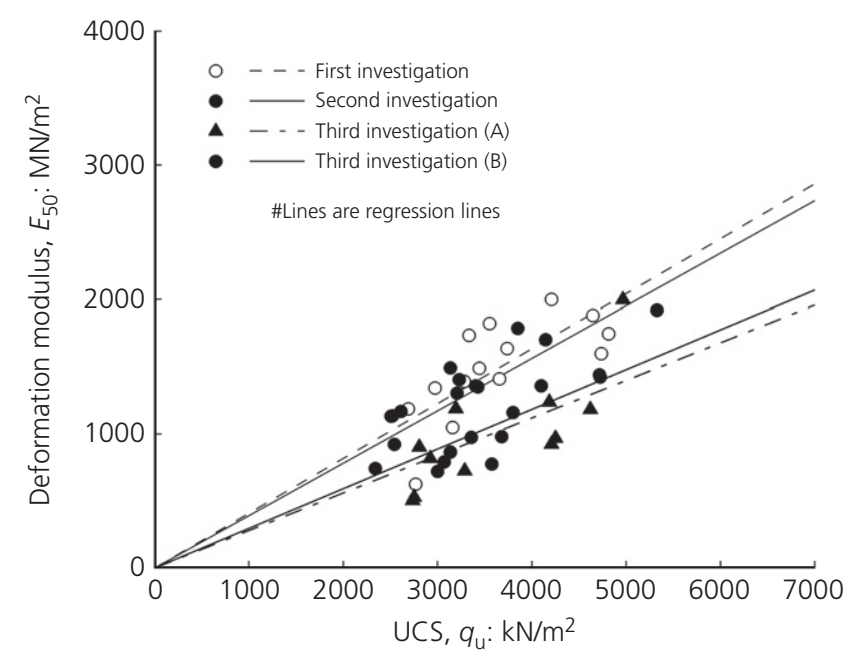

Figure 16. Deformation modulus and UCS calcium content in the third investigation was similar to that in the first investigation. Therefore, it is reasonable to consider that the calcium content was incidentally low in the second investigation. The water content in that investigation was also low. The low content of both calcium and water could support the possibility of preserving strength in the second investigation.

\subsection{2 $\mathrm{pH}$ value and EC}

Table 4 shows $\mathrm{pH}$ and EC values. The measured $\mathrm{pH}$ averaged 11.7 and 11.4 in blocks $\mathrm{A}$ and $\mathrm{B}$, respectively; its $\mathrm{CoV}$ was low. This indicated that the treated soil was entirely in a highly alkaline atmosphere. The measured ECs of blocks A and B were 0.52 and $0.31 \mathrm{~S} / \mathrm{m}$, respectively. These values were sufficiently high, considering that the exposed surface had a low EC of approximately $0 \cdot 1 \mathrm{~S} / \mathrm{m}$, as mentioned in the next chapter. It was verified by indirect means that calcium remained in the treated soil even after 37 years.

\section{Deterioration properties near the surface}

\subsection{Needle-penetration resistance}

Needle-penetration tests were conducted against the surface of the specimens in the second and third investigations to investigate deterioration. Test specimens were taken from numbers $9-12$ and $\mathrm{H} 1-\mathrm{H} 3$ of block $\mathrm{B}$ in the second investigation and numbers $1-4$ of block $A$ and numbers $14-17$ of block $\mathrm{B}$ in the third investigation. A needle was penetrated into the surface three times.

Figure 17 shows representative results; it also includes the results of other tests mentioned in the following section. Figures 17(a)-17(c) show the results of the second investigation, and a change in gradient can be observed in (a) and (b), showing the results of top surfaces. The change points were 19 and $23 \mathrm{~mm}$ from the surface; the average was approximately $21 \mathrm{~mm}$ based on all test cases. On the other hand, there was no change gradient in (c), showing the results of the middle of the core. The deterioration depth was approximately $21 \mathrm{~mm}$ in the second investigation.

Figures 17(d)-17(i) show the results in the third investigation; a change in gradient can be observed in (d)-(f), showing the results of the top surfaces. The change points were 26, 27 and $25 \mathrm{~mm}$. The average was approximately $28 \mathrm{~mm}$ based on all test cases. No change in gradient was found in $(\mathrm{g})$, which shows the middle core results. The gradient in $(\mathrm{g})$ was large and was similar to one of the specimens deeper than the change points in (d)-(f); it was observed that it had not deteriorated. The deterioration depth was expected to be approximately $28 \mathrm{~mm}$ in the third investigation. Figure 18 shows the deterioration depth against curing period and also shows results obtained by other researchers. The speed of deterioration was reasonable, considering past reports.

An interesting characteristic, seen in Figures 17(h) and 17(i), shows the results of the bottom surfaces. They show no change 

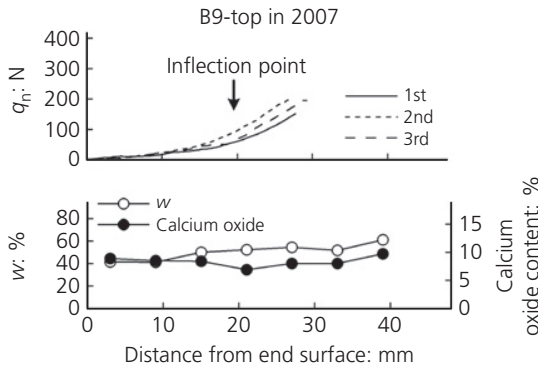

(a)
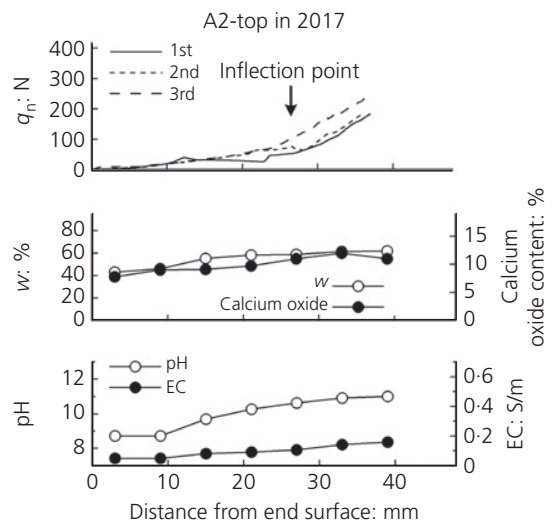

(d)
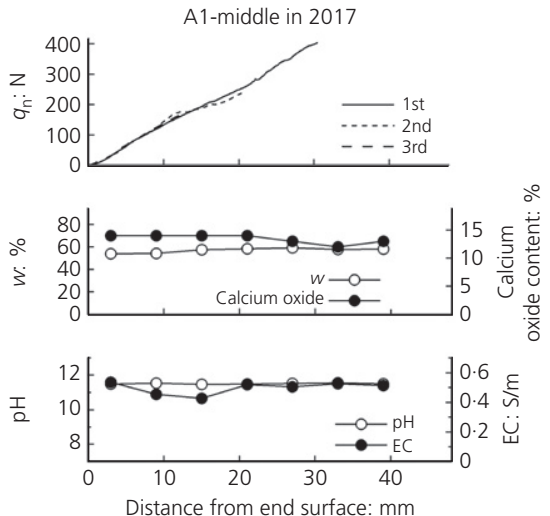

(g)
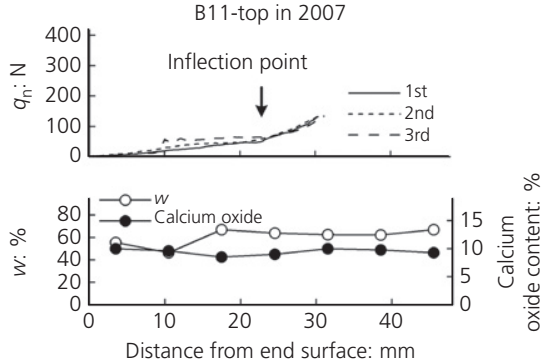

(b)
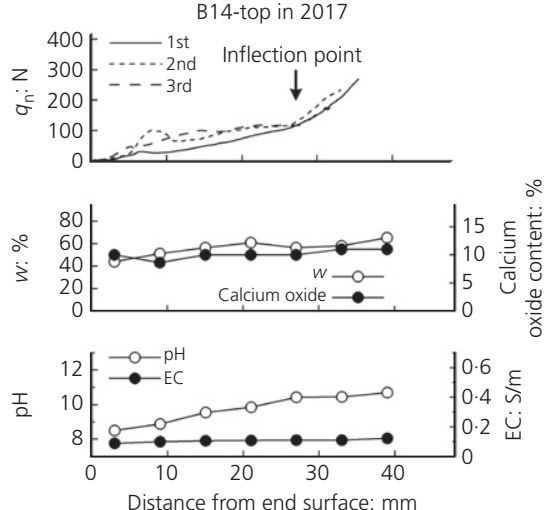

(e)
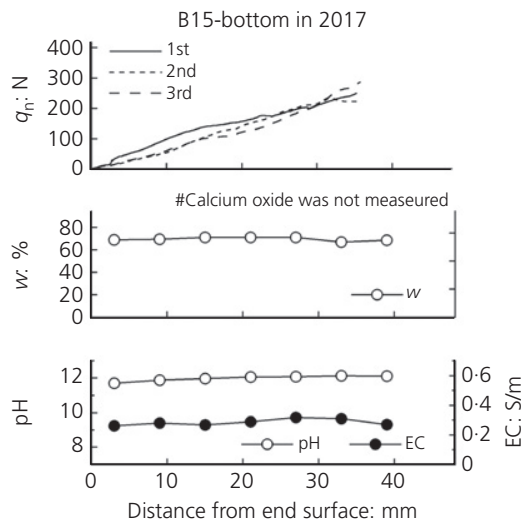

(h)
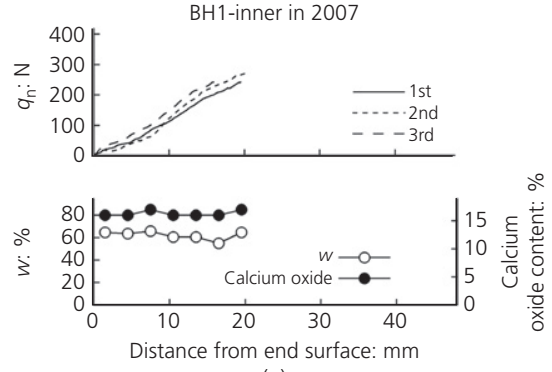

(c)
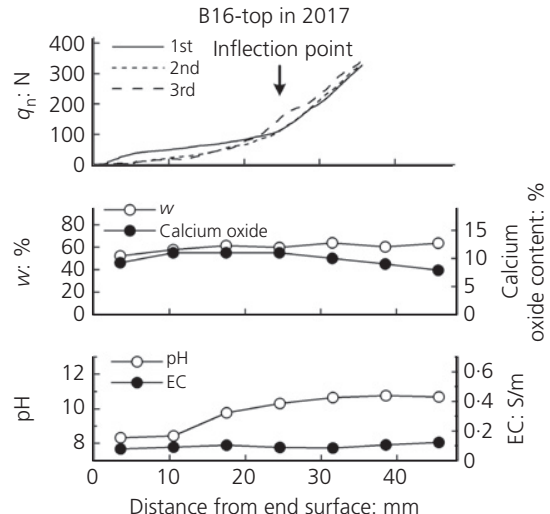

(f)
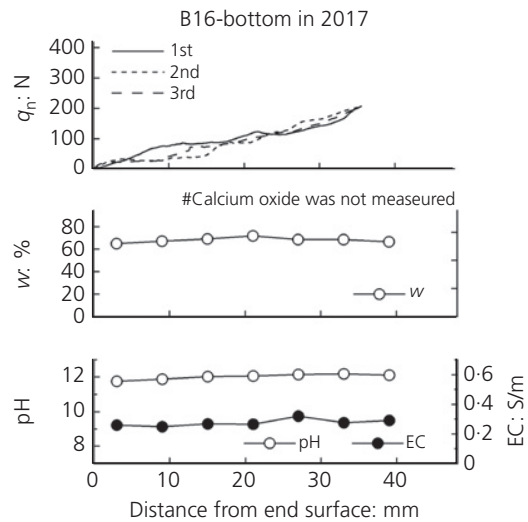

Figure 17. Measurements near the surface of treated soil; 1st, 2nd and 3rd represent the first investigation, second investigation and third investigation respectively.

gradient; however, the gradients were clearly smaller than those of $(\mathrm{g})$. The results in the second investigation showed the same characteristic. ECs were also small, as shown in the following section. The small gradients and ECs indicate some type of state change. If this state change was due to deterioration, it can be concluded that the deterioration properties of the top and bottom surfaces were different. This might result from differences in the saturation condition.

\subsection{Other test results}

The deterioration depth was also investigated by implementing calcium content, $\mathrm{pH}$ and EC tests. The results are shown in Figure 17, including water content. These values were measured by penetration test specimens divided at intervals of $6 \mathrm{~mm}$, excluding several specimens divided at intervals of $3 \mathrm{~mm}$ or $7 \mathrm{~mm}$. Figures 17(a), 17(b) and 17(d)-17(f) demonstrated deterioration in the penetration tests and showed low calcium contents of approximately $10 \%$. The closer the measuring points were to the surface, the lower was the calcium content. On the other hand, the calcium contents were approximately $15 \%$ in Figures 17(c) and 17(g), which demonstrated non-deterioration. Calcium would be discharged from the surface exposed to the soil; however, there was no sharp change around the point of the change gradient observed in the penetration tests.

Figures 17(d)-17(f) show low pH values of less than 11. The $\mathrm{pH}$ was especially small near the surface. $\mathrm{pH}$ within $10 \mathrm{~mm}$ from the surface was approximately $8-9$. On the other hand, 


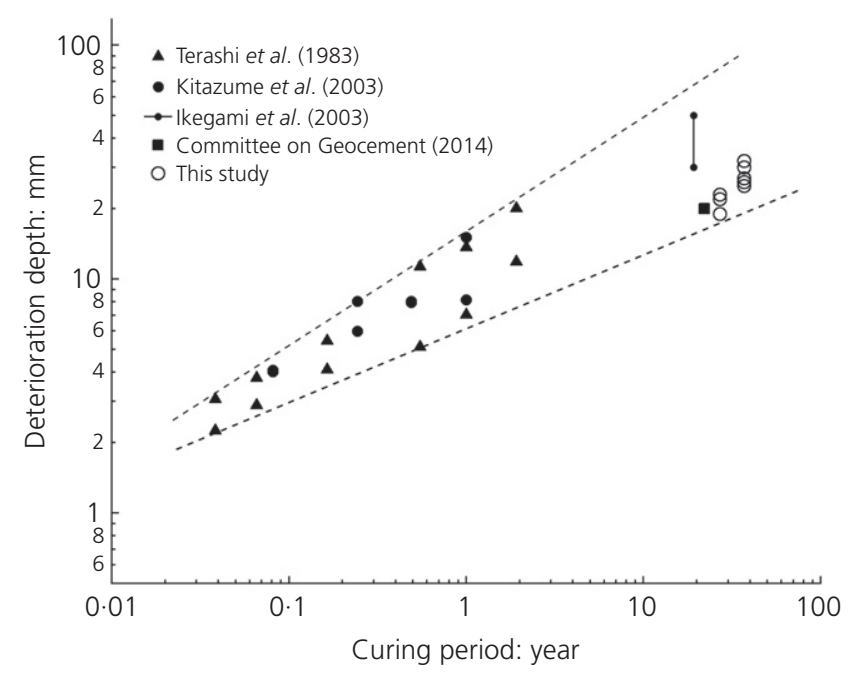

Figure 18. Change of deterioration depth over time

Figure $17(\mathrm{~g})$ shows a high $\mathrm{pH}$ of approximately 11-12; the middle of the core was in a highly alkaline atmosphere. This demonstrated that the top of the treated soil was neutralised. With regard to EC, Figures 17(d)-17(f) show a low value of approximately $0.1 \mathrm{~S} / \mathrm{m}$, whereas Figure $17(\mathrm{~g})$ shows a high value of more than $0.4 \mathrm{~S} / \mathrm{m}$. These results indicate that the ionisation tendency at the top of the treated soil became weak. The low $\mathrm{pH}$ and EC indirectly verified that calcium was discharged from the surface. In addition, no sharp change in the plots of $\mathrm{pH}$ and $\mathrm{EC}$ as well as in calcium content was observed, although the penetration tests showed a change in gradient. It can be considered that deterioration decreased the calcium content, $\mathrm{pH}$ and $\mathrm{EC}$, at first, and that the strength of the treated soil sharply decreased to reach the limit.

Finally, the relationship between calcium content, $\mathrm{pH}$ and EC was examined. Figure 19 shows calcium content and EC against $\mathrm{pH}$. The plots were obtained from specimens used for UCS and needle-penetration tests. Figure 19(a) indicates that calcium content and $\mathrm{pH}$ had a non-linear relationship. The calcium content was below $12 \%$ when the $\mathrm{pH}$ was below 11. These values divided the specimens with or without deterioration. Figure 19(b) also shows the non-linear relation between EC and $\mathrm{pH}$. As EC fell below $0.2 \mathrm{~S} / \mathrm{m}, \mathrm{pH}$ decreased from approximately 11 to approximately $8-9$. These values also indicate the boundary with and without deterioration. The treated soil examined in this study had several deterioration indicators, such as calcium oxide content of $12 \%, \mathrm{pH}$ of 11 and $\mathrm{EC}$ of $0 \cdot 2 \mathrm{~S} / \mathrm{m}$. As the treated soil had smaller values, it would lose strength to reach the limit.

\section{Conclusions}

This paper presented the changes in UCS, wet density, water content and calcium content of quicklime-treated soil cured for more than 37 years. Additionally, needle-penetration resistance, $\mathrm{pH}$ and $\mathrm{EC}$ were measured to reveal deterioration properties

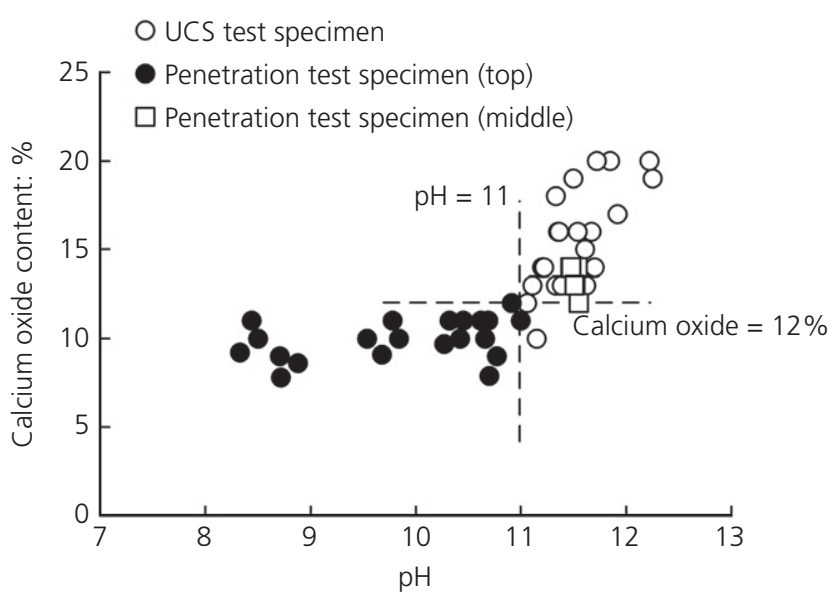

(a)

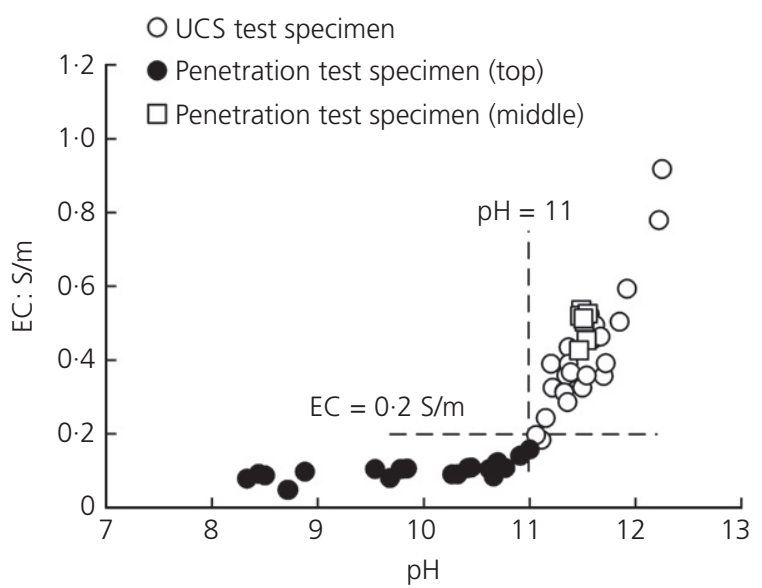

(b)

Figure 19. Relationships between (a) calcium oxide content and $\mathrm{pH}$ and (b) EC and $\mathrm{pH}$

from the surface exposed to soil. The major conclusions are as follows.

(a) The UCS largely increased at first and then remained constant throughout the 37 year curing period. It can be concluded that quicklime treatment is effective for a long period. On the other hand, the deformation modulus tended to decrease and the reduction ratio reached $28-32 \%$.

(b) The calcium content also remained constant for 37 years, although a low content was observed in the second investigation. In the third investigation, the $\mathrm{pH}$ value and EC were measured; they showed a high alkali atmosphere and ionisation tendency.

(c) Needle-penetration tests indicated deterioration from the surface of the treated soil. The average deterioration depth was $28 \mathrm{~mm}$ at the top surfaces in the third investigation. On the other hand, the deterioration depth could not be determined at the bottom surfaces although an indication of deterioration could be observed. These findings might result from differences in the saturation condition. 
(d) Calcium content, $\mathrm{pH}$ and $\mathrm{EC}$ were low near the surface. No sharp change could be observed around the point of the change gradient shown in the penetration tests. The indicators for deterioration of the present treated soil were a calcium oxide content $12 \%, \mathrm{pH}$ of 11 and $\mathrm{EC}$ of $0.2 \mathrm{~S} / \mathrm{m}$.

The strength of the in situ quicklime-treated soil remained, even after 37 years. However, the treated soil deteriorated from the surface. It is important to understand deterioration near the surface as well deterioration of the internal parts of treated soil. After the third investigation, the treated soil was again cured in the soil tank and a further investigation will be conducted in the future.

\section{Acknowledgements}

This study was supported by the Japan Society for the Promotion of Science, Grant-in-Aid for Scientific Research (B), number $15 \mathrm{H} 04042$. The authors gratefully acknowledge this financial support. In addition, the first investigation was assisted by Dia Consultants Co. and the second and third ones were assisted by Kiso-Jiban Consultants Co. The authors are deeply grateful for this assistance.

\section{REFERENCES}

Broms BB (1999) Design of lime, lime/cement and cement columns. Proceedings of the International Conference on Dry Mix Methods for Deep Soil Stabilization. Balkema, Rotterdam, the Netherlands, pp. 125-153.

Broms BB and Boman P (1975) Lime stabilized columns. Proceedings of the 5th Asian Regional Conference on Soil Mechanics and Foundation Engineering. Indian Institute of Science, Bangalore, India, vol. 1, pp. 227-234.

Broms BB and Boman P (1978) Stabilization of Soil With Lime Columns - Design Handbook, 2nd edn. Department of Soil and Rock Mechanics, Royal Institute of Technology, Stockholm, Sweden. Broms BB and Boman P (1979) Lime columns - a new foundation method. Journal of the Geotechnical Engineering Division 105(4): 539-556.

CDIT (Coastal Development Institute of Technology) (2014) Technical Manual of Deep Mixing Method in Ports and Airports. CDIT, Tokyo, Japan (in Japanese).

Committee on Geocement (2014) A study on long term stability of soil-cement columns improved by geocement, cement and concrete. Cement and Concrete, no. 804, pp. 9-14 (in Japanese).

Hayashi H, Nishikawa J, Ohishi K and Terashi M (2003) Field observation of long-term strength of cement treated soil. Proceedings of the 3rd International Conference on Grouting and Ground Treatment. ASCE, Reston, VA, USA, vol. 1, pp. 598-609.

Holm G (1999) Applications of dry mix methods for deep soil stabilization. Proceedings of the International Conference on Dry Mix Methods for Deep Soil Stabilization. Balkema, Rotterdam, the Netherlands, pp. 3-13.

Ikegami M, Ichiba T, Ohishi K and Terashi M (2003) Long-term strength change of cement treated soil at Daikoku Pier. Proceedings of Soft Ground Engineering in Coastal Areas. Balkema, Lisse, the Netherlands, pp. 241-246.

JCA (Japan Cement Association) (1967) F-18, Report of Joint Tests on Estimation of Mix Proportions of Hardened Concretes. Japan Cement Association, Tokyo, Japan (in Japanese).
JGS (Japanese Geotechnical Society) (2015) Japanese Geotechnical Society Standards, Laboratory Testing Standards of Geomaterials. Japanese Geotechnical Society, Tokyo, Japan.

JSCE (Japan Society of Civil Engineers) (1991) Guideline of Investigation and Test of Soft Rock (Draft). JSCE, Tokyo, Japan (in Japanese).

Kitazume M and Takahashi H (2008) Long term property of lime treated marine clay. Journal of Japan Society of Civil Engineers, Series $C$ 64(1): 144-156 (in Japanese).

Kitazume M and Takahashi H (2009) 27 years' investigation on property of in-situ quicklime treated clay. Proceedings of the 17th International Conference on Soil Mechanics and Geotechnical Engineering. Millpress Science Publishers, Rotterdam, the Netherlands, pp. 2358-2361.

Kitazume M and Terashi M (2013) The Deep Mixing Method. CRC Press/Balkema, Leiden, the Netherlands.

Kitazume M, Nakamura T, Terashi M and Ohishi K (2003) Laboratory tests on long-term strength of cement treated soil. Proceedings of the 3rd International Conference on Grouting and Ground Treatment. ASCE, Reston, VA, USA, vol. 1, pp. 586-597.

Nakamura T and Kitazume M (2006) Laboratory tests on durability of cement treated soils. Technical Note of the Port and Airport Research Institute, no. 1128 (in Japanese).

Okumura T, Mitsumoto T, Terashi M, Sakai T and Yoshida T (1972) Deep-lime-mixing method for soil stabilization. Report of the Port and Harbour Research Institute 11(1): 67-106 (in Japanese).

PWRC (Public Works Research Center) (2004) Technical Manual on Deep Mixing Method for On Land Works. PWRC, Tokyo, Japan (in Japanese).

Terashi M and Kitazume M (1992) An investigation of the long term strength of a lime treated marine clay. Technical Note of the Port and Harbour Research Institute, no. 732 (in Japanese).

Terashi M, Okumura T and Mitsumoto T (1977) Fundamental properties of lime-treated soils. Report of the Port and Harbour Research Institute 16(1): 3-28 (in Japanese).

Terashi M, Tanaka H and Okumura T (1979) Engineering properties of lime-treated marine soils and D.M. method. Proceedings of the 6th Asian Regional Conference on Soil Mechanics and Foundation Engineering. Southeast Asian Society of Soil Engineering and Institution of Engineers, Singapore, Singapore, vol. 1, pp. 191-194.

Terashi M, Tanaka H, Mitsumoto T, Niidome Y and Honma S (1980) Fundamental properties of lime and cement treated soils (2nd report). Report of the Port and Harbour Research Institute 19(1): 33-62 (in Japanese).

Terashi M, Tanaka H, Mitsumoto T, Honma S and Ohhashi T (1983) Fundamental properties of lime and cement treated soil (3rd report). Report of the Port and Harbour Research Institute 22(1): 69-96 (in Japanese)

\section{How can you contribute?}

To discuss this paper, please email up to 500 words to the editor at journals@ice.org.uk. Your contribution will be forwarded to the author(s) for a reply and, if considered appropriate by the editorial board, it will be published as discussion in a future issue of the journal.

Proceedings journals rely entirely on contributions from the civil engineering profession (and allied disciplines). Information about how to submit your paper online is available at www.icevirtuallibrary.com/page/authors, where you will also find detailed author guidelines. 